\title{
MULTI-TEMPORAL SPATIAL DATA AFRICA
}

\author{
R. Becker \\ Geodyn Technology, Dubai UAE - P.O. Box 371838 DAFZ rolf.becker@ geodyn.com
}

\begin{abstract}
KEY WORDS: multi temporal aerial photography, geospatial dynamic data, analog/digital conversion, detail-matching
\end{abstract} georeferenced imagemaps national heritage

\begin{abstract}
:
To plan for the future, it is essential to understand the present as well as the past. Hindsight is the most valuable asset when examining how to proceed. Apart from natural catastrophes, conditions do not happen, they develop! This paper proposes that in order to change or influence conditions, not only must their present state be considered, but it is essential to investigate what triggered them in the first place. This requires access to records that might have to reach back for as much as many years. In Africa, such records are hard, if not impossible, to retrieve. Moreover, whatever records can be located are likely to have been compiled by a variety of different agencies, each presenting their own versions of events and consequently, often contradictory. To overcome such problems, it is proposed to use aerial photography that has been taken and hopefully archived over the past decades. Such aerial imagery can provide temporal geospatial data to trace the course, interaction and consequences of events. Combined with more recent satellite imagery, they provide unbiased evidence of past developments that can now be analyzed and assessed based on our awareness of today. This presentation deals with advanced data conversion and automated processing procedures conceived for convenient and user-friendly information access, as well as data mining and bigdata processing.
\end{abstract}

\section{INTRODUCTION}

This presentation draws attention to the vast amount of Aerial Photography that has been taken over the last hundred years. These images portray the heritage of contemporary Africa in detail, thereby providing the opportunity and potential to reassess development in the light of present awareness. These significant conclusions can form a valuable asset for consideration in the planning for tomorrow. However, as a precondition, there is an urgent need to research repositories where these aerial films and their by-products have been archived and, when located, a further requirement that they be converted into a digital format necessary for computer assisted analysis. This presentation is an appeal the geospatial community to provide assistance in the effort to locate the whereabouts of the photography taken over Africa during the last century in support of numerous development projects by a multitude of different countries and funding agencies.

\section{MULTI-TEMPORAL SPATIAL DATA PROCESSING}

\subsection{Appraise the past to evaluate plans for tomorrow}

Conditions do not happen, they develop. Consequently, the data to define them needs to be dynamic, i.e. temporally attributed to monitor the course of past events. To improve conditions, first we need to find out what caused them, in a similar manner to a doctor's anamnesis. Changes grow on us, mostly imperceptibly, only to become apparent by the time they cause a problem. By then we might no longer recall what might have triggered them, having at the time still being unaware of their relevance. Redressing a problem solely on the basis of presented evidence might bring relief, but it is likely to distract from the most important issue, namely what has led to a certain condition in the first place. To manage and develop our infrastructure and take care to protect our natural environment, we must take into consideration their increasingly dynamic interaction. We cannot afford to base action on predictions without first considering the lessons from the past. Hindsight is a powerful asset when planning for tomorrow. Prediction of the future relies on storytelling, unless we have applied the lessons we have learnt from the past. We must not only understand the present situation but, more importantly, try to first identify what triggered the developments that led to our present state. We need to appraise past measures and actions in the light of our current awareness. For this we need to be familiar with the background. But how?

Hundreds of millions of aerial photographs exist worldwide at the custodians of aerial films which are mostly in the archives of National Survey organizations, various Ministries and, of course, the Military. These aerial films constitute an important record of a country's heritage. These films are mostly carefully locked away and thereby becoming less and less accessible. The necessary infrastructure, along with the required expertise required to access and scrutinize conventional aerial photography has been obliterated. Like literature held in old libraries, conventional aerial photography can no longer be studied and analyzed unless the content is converted into digital format and thereby become accessible for computerized data extraction and data mining.

Multi-temporal aerial photography exists practically all over the world - specifically in areas with frequent development cycles. This is supplemented by high resolution satellite imagery that has become widely available over the past 15 years. Together, this imagery provides unassailable evidence of the development of our infrastructure and its environmental impact, permitting us to draw conclusions as to the effectiveness of past actions in the light of current awareness. 


\subsection{Technological impasse}

There are four elements which hamper aerial film access:

- The whereabouts of the aerial films is widely unknown.

- $\quad$ Aerial photography of the past is generally not available in a digital format

- Most data are only loosely tied to a geographic reference system, if at all.

- Automated change detection and associated object identification systems are still in an elementary state.

While the first 3 items above are technically under control, automated change detection and automatic object identification still pose a challenge for automated assessment, especially where very old aerial films might not have adequate clarity.

\subsection{Comprehensive analogue/digital conversion of aerial photography}

Geodyn engages in the comprehensive conversion of analog aerial photography into a digital format for any available aerial photography for which the original films or contact prints can be accessed. This provides the basis to retrace development over time and identify the cause and effect of actions and measures taken since, as well as to appraise the consequences thereof. Using this material, the effects of the development efforts can be assessed in an objective manner in the light of current awareness. Geodyn's key personal have a combined expertise of over 150 years in the field of aerial photography, putting the company in a privileged position to develop novel procedures, software and equipment as well as the necessary expertise to convert huge quantities of aerial photography, thereby reducing cost and time requirement by a magnitude that had so far not been considered achievable.

\subsection{Georeferenced image maps}

Geodyn technology goes beyond the mere conversion of analogue aerial photography to a digital format. Its services include the compilation of each available photo coverage into corresponding image maps, so they can be overlaid on current maps or satellite imagery with detailmatching accuracy. This is conceived so as to make the data easily accessible to a wide range of applications. Town, planning, environmental studies forestry, land management, agriculture, mining, archaeology, cadaster and flood control to name a few. Aerial photography taken many decades ago, can now be displayed in $3 \mathrm{D}$, on standard computer screen and even as printouts. Training is no longer required. Unencumbered access to these image data now opens up the usage of aerial imagery to domains where the information provided by imagery was previously too complex to access. The essence of information is availability at the instant it is needed.

\subsection{Date conversion imperatives}

In view of the potential clients spread thinly all over the world, Geodyn operates internationally and exclusively through companies that have a background in the spatial data acquisition and processing domain. By drawing on local resources along with Geodyn's technology, equipment, software and project management ensures project success. An essential aspect of Geodyn's operation is performed at the client's premises and is designed to involve their personnel to the fullest extent. The time requirement for a project depends not only on the number of frames and films to be converted, but is also influenced by the effort required to geo-reference the imagery. The corresponding procedure is highly automated, but still dependent on accuracy requirements and availability of support data such as film reports, photo-indices or possibly aero-triangulation data. With the advent of global high-resolution imagery base maps such World Imagery in ArcGIS Online, the processes to accurately geo-reference imagery have significantly improved to the point that it can be highly automated.

\subsection{Novel opportunities}

The conversion and georeferencing of archives of aerial films creates novel opportunities. By being geometrically as well as temporally referenced, it enables us to reach conclusions based on identifying relevant correlation though simultaneous and synchronized analysis of multitudes of attributes. This will provide insight into the development of phenomena that until now have not been identified.

\subsection{Sample data}

Multi-temporal images of the outskirts of Addis Ababa, see Figure 1. These images have been taken over a period of over 60 years_by different international aerial survey companies. The films are carefully archived at the Ethiopian Mapping Agency, which contains over 200,000 frames, taken at different scales. Presently they have been digitized with at 20-micron resolution. Converted into multi-temporal image maps can be overlaid with detail-matching accuracy, even for stereoscopic viewing.

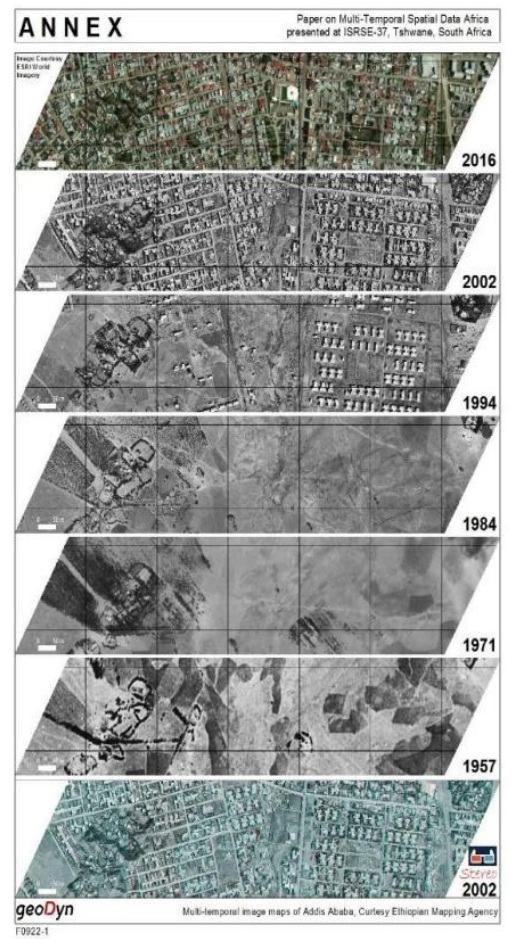

Figure 1. Multi-temporal image maps of Addis Ababa 
The International Archives of the Photogrammetry, Remote Sensing and Spatial Information Sciences, Volume XLII-3/W2, 2017 37th International Symposium on Remote Sensing of Environment, 8-12 May 2017, Tshwane, South Africa

\section{CONCLUSION}

Multi-temporal spatial data define the location of objects or events in space as well as time. As such, they reference relevant data layers required in information finding. The conclusion drawn in the light of current awareness with respect to identifying the consequence and the measure taken in the past, can provide us with valuable input in our quest to shape our future. This presentation is an appeal to the African Geospatial Community to support the establishment of an inventory of the estimated million aerial photograph that have been taken over Africa as first step to make this untapped wealth of data readily accessible. Equally important, converting this photography into a digital format and geo-referencing can make a major contribution to safeguard the National Heritage of regions where such historical information is only scarcely documented. 